\title{
Acute muscular weakness in children
}

\author{
Fraqueza muscular aguda em crianças
}

Ricardo Pablo Javier Erazo Torricelli1,2

\begin{abstract}
Acute muscle weakness in children is a pediatric emergency. During the diagnostic approach, it is crucial to obtain a detailed case history, including: onset of weakness, history of associated febrile states, ingestion of toxic substances/toxins, immunizations, and family history. Neurological examination must be meticulous as well. In this review, we describe the most common diseases related to acute muscle weakness, grouped into the site of origin (from the upper motor neuron to the motor unit). Early detection of hyperCKemia may lead to a myositis diagnosis, and hypokalemia points to the diagnosis of periodic paralysis. Ophthalmoparesis, ptosis and bulbar signs are suggestive of myasthenia gravis or botulism. Distal weakness and hyporeflexia are clinical features of Guillain-Barré syndrome, the most frequent cause of acute muscle weakness. If all studies are normal, a psychogenic cause should be considered. Finding the etiology of acute muscle weakness is essential to execute treatment in a timely manner, improving the prognosis of affected children.
\end{abstract}

Keywords: muscle weakness; poliomyelitis; Guillain-Barré syndrome;

botulismo; myasthenia gravis.

RESUMO

A fraqueza muscular aguda (FMA) na criança é uma emergência pediátrica. Durante a abordagem diagnóstica, é crucial obter uma anamnese detalhada que inclua: início da fraqueza, história de estados febris associados, ingestão de substâncias tóxicas/toxinas, imunizações e história familiar. 0 exame neurológico também deve ser acurado. Nesta revisão, nós descrevemos as doeças mais frequentemente associadas com FMA, agrupadas pelo local de origem (desde o neurônio motor superior até a unidade motora). A detecção precoce de aumento de CK pode levar ao diagnóstico de miosite, e a hipopotassemia orienta para o diagnóstico de paralisia periódica. A oftalmoparesia, ptose e sinais bulbares são sugestivos de miastenia gravis ou de botulismo. Fraqueza distal e hiporeflexia são dados clínicos da síndrome de Guillain Barré (SGB), a mais frequente causa de FMA. Se todos os estudos são normais, uma causa psicogênica pode ser considerada. A busca da etiologia da FMA é essencial para que o tratamento seja feito a tempo, melhorando o prognóstico da criança afetada.

Palavras-chave: debilidade muscular; poliomielite; síndrome de Guillain-Barré; botulismo; miastenia gravis.

Acute muscle weakness is a major neurological emergency in pediatrics. It is defined by muscle weakness or acute flaccid paralysis, with clinical onset in less than five days, according to the World Health Organization (WHO) definition.

Causes of acute muscle weakness include diseases that compromise the descending motor pathway, from the upper motor neuron to the motor unit are, as is described in table $1 .{ }^{2,3}$

Acute disorders of the motor unit are generally expressed as symmetrical weakness, associated with diminished deep tendon reflexes ${ }^{4,5}$. Brain diseases can produce initial hypotonic paralysis, but weakness is usually unilateral or asymmetric (hemiparesis), and pyramidal signs appear rapidly (hyperreflexia, extensor plantar response), which can help locate the lesion above the motor unit ${ }^{2}$. The objective of this review is to provide the clinical elements for evaluating children suffering from acute muscle weakness. Most importantly, an early, detailed case history should be taken; it must be repeated subsequently, in order to correct data errors or omissions that may misdirect the diagnosis. The clinical history must include previous symptoms, location of weakness at onset (ocular, bulbar, proximal or distal muscles), sequence and rate of progression of paralysis, exposure to drugs and toxins, immunizations, previous episodes of weakness and remote and family history (e.g. neonatal).

In the child evaluation, it is important to consider vital signs and respiratory functioning. Neurological examination must address the distribution of weakness, impaired cranial nerves, and sensory and autonomic dysfunction. The degree of muscle weakness should be measured according to the Medical Research Council scale, which is classified into five levels: 0 = no muscle contraction; 1 = visible or palpable contraction, but no movement; 2 = movement of the joint in a

${ }^{1}$ Hospital Luis Calvo Mackenna, Provencia, Santiago, Chile;

${ }^{2}$ Clinica Alemana, Vitacura, Santiago, Chile.

Correspondence: Ricardo Pablo Javier Erazo Torricelli; Hospital Luis Calvo Mackenna, Antonio Varas, 360; Provencia, Santiago, Chile; E-mail: ricardoerazo@yahoo.com Conflict of interest: There is no conflict of interests to declare.

Received 12 July 2016; Accepted 29 July 2016 
horizontal plane only (resistance of gravity must be removed); 3 = movement against gravity, but the examiner's resistance must be removed; 4 = movement against gravity and resistance, but with reduced strength; $5=$ normal muscle strength ${ }^{6}$.

Assessments or laboratory tests to determine the etiologic diagnosis of acute muscle weakness should be performed sequentially. Some key tests must be conducted immediately, and more complex studies might be performed subsequently, as detailed in Table 2

In the early hours, the most important element to guide the diagnosis is the neurological evaluation. Diseases of the peripheral nerves affect distal muscles first, and myopathies or lower motor neuron diseases involve mainly the proximal muscle groups. Although this information is very useful and orienting, there are exceptions. GBS can show predominantly proximal weakness; and muscular diseases may exhibit distal weakness, as can be seen in acute infectious myositis and, rarely, in periodic paralysis s.3 $^{2,3}$

Diseases that most commonly cause acute muscle weakness in children are described below.

\begin{tabular}{|c|}
\hline Upper motor neuron \\
\hline Encephalitis \\
\hline Encephalomyelitis \\
\hline Brainstem encephalitis \\
\hline Transverse myelopathy \\
\hline Postinfectious myelitis (demyelinating) \\
\hline Neuromyelitis optica (Devic's disease) \\
\hline Motor Unit \\
\hline Lower motor neuron \\
\hline Wildtype / vaccinal polio virus \\
\hline EV 71 ,West Nile Virus, EV 68 \\
\hline Peripheral nerve \\
\hline Guillain Barré syndrome and variants \\
\hline Porphyric neuropathy \\
\hline Diphtheritic neuropathy \\
\hline Heavy-metal poisoning \\
\hline Paralytic shellfish poisoning \\
\hline Tick parálisis \\
\hline Neuromuscular junction \\
\hline Presynaptic \\
\hline Botulism \\
\hline Spider venom (latrodectus mactans) \\
\hline Synaptic \\
\hline Organophosphate poisoning \\
\hline Post synaptic \\
\hline Autoimmune myasthenia gravis: Myasthenic crisis \\
\hline Muscle \\
\hline Acute infectious myositis \\
\hline Polymyositis / dermatomyositis \\
\hline Rhabdomyolysis (metabolic myopathies) \\
\hline Periodic Paralysis \\
\hline Critical Illness myopathy \\
\hline Psycogenic \\
\hline Psycogenic paralysis \\
\hline
\end{tabular}

\section{UPPER MOTOR NEURON DISEASES}

\section{Acute disseminated encephalomyelitis}

Acute disseminated encephalomyelitis can produce acute muscle weakness when there is an involvement of the cerebellum, brainstem or spinal cord. On these occasions, central nervous system involvement tends to be extensive, and flaccid paralysis is associated with cranial nerve dysfunction (including palpebral ptosis, external ophthalmoparesis and facial diparesis). Note that the encephalopathy may be brief and subtle, and pyramidal signs may not be initially observed. ${ }^{8}$

Brain and spinal magnetic resonance imaging (MRI) must be obtained to determine the diagnosis.

\section{Brainstem encephalitis (Bickerstaff)}

In brainstem encephalitis, there is bilateral motor deficit and cranial nerve involvement, with ophthalmoparesis and frequent pupillary signs (intermediate or mydriatic, nonreactive pupils). Pyramidal signs appear rapidly and the diagnosis is confirmed by brain MRI. ${ }^{8}$

\section{Acute myelitis}

Acute myelopathy of diverse origin can cause flaccid paraparesis or tetraparesis, presenting as acute muscle weakness. Traumatic myelopathy is an obvious diagnosis in the majority of cases and will not be discussed here. Transverse myelopathy of various etiologies (including tumors) shows typical signs of myelopathy, with sensory level and bladder/anal involvement, adding pyramidal signs in later days. Demyelinating diseases are frequently associated with acute muscular weakness of spinal origin, and a demyelinating myelopathy can be found in post-infectious myelitis, as a part of encephalomyelitis, and in neuromyelitis optica,

Table 2. Laboratory tests for acute muscle weakness.

A. Mandatory studies
Serum creatine kinase (CK)
Plasma electrolytes
Complete blood count (CBC)
Toxicological panel
Tensilon or neostigmine test
B. Additional studies
Cerebral and spinal MRI
Lumbar puncture: CSF cytochemical testing and
specific antibodies
Neurophysiological studies: EMG, nerve conduction,
single-fiber EMG
Detection of botulinum toxin in stool
Detection of poliovirus or other viruses in stool


also known as Devic's disease. In demyelinating forms, spinal involvement is usually extensive and the clinical picture can be less accurate, without a well-defined sensory level (although sphincter involvement is frequent). Spinal cord and brain MRI can confirm the diagnosis. Detection of specific antibodies may be helpful in neuromyelitis optica. ${ }^{8}$

\section{DISEASES OF MOTOR UNIT}

Motor unit diseases constitute the vast majority of cases of acute weakness in children. They include diseases of lower motor neuron, peripheral nerve, neuromuscular junction, and muscle.

\section{LOWER MOTOR NEURON DISEASES}

\section{Poliomyelitis}

Poliomyelitis is defined as the compromise of the anterior horns of the spinal cord, secondary to a poliovirus infection. The term "acute flaccid paralysis" and the global monitoring program for this entity (polio) declared by the WHO in the decade of 1980s, were created with the objective of eradicating poliovirus worldwide. ${ }^{1,3}$

Chile was the third country to eradicate polio infections caused by wildtype virus, in 1975. Later, in 1991, Latin America became free of wildtype cases, as a result of strict vaccination programs; today, only vaccinal polio cases can be found. Polio manifests as cold or flu symptoms in over $99 \%$ of cases. Only $0.2-0.5 \%$ of the total cases show neurological signs (asymmetric weakness and decreased reflexes, proportional to the degree of weakness) $)^{8,9}$.The cerebrospinal fluid shows pleocytosis.

Vaccinal polio cases may appear in up to $1 / 750,000$ vaccinated child, and they are more common after the first doses of the vaccine ${ }^{1}$. In our experience, two infants (aged 2.5 months at the time of assessment) showed symmetrical muscle weakness and areflexia.

The WHO has issued a global alert, since polio cases can still be found in some countries. Therefore, the vaccination program must be maintained strictly on a worldwide scale ${ }^{9,10}$

There are cases of poliomyelitis caused by other viruses, such as West Nile virus, enterovirus 71, enterovirus 68, Coxsackie virus and others. Thus, proper identification of the causative virus is mandatory in cases of acute flaccid paralysis with polio symptoms and signs ${ }^{1,11}$

\section{PERIPHERAL NERVE DISEASES}

There are infectious, traumatic, toxic and toxin-related causes of acute muscle weakness that can affect peripheral nerves. We will describe only the most common conditions.

\section{Guillain-Barré syndrome}

GBS, defined as an acute, monophasic sensorimotor polyradiculoneuropathy with a post-infectious/immunemediated origin, is the leading cause of acute muscle weakness in developed countries. ${ }^{13,14}$

It has an incidence of $0.5-1.5$ cases per 100,000 individuals in the population aged $0-17$ years ${ }^{13,14}$.

The most common form of presentation is acute inflammatory demyelinating polyneuropathy, representing 85-90\% of cases in North America, Europe and the majority of developed countries ${ }^{13,14}$.

It starts with distal weakness of the lower limbs, with an ascending progression (from distal to proximal) within hours or days, two to four weeks after a respiratory or gastrointestinal infection. In 30-40\% of cases there is an involvement of cranial nerves, most commonly cranial nerve VII. In severe cases, respiratory muscles are affected. Lower extremity or lower back pain is common in the early days of the disease ${ }^{13,14,15,16}$.

Clinically, symmetrical weakness and hyporeflexia or areflexia can be observed, with mild sensory involvement and a series of autonomic disturbances: cardiac dysrhythmias, orthostatic hypotension, and hypertension ( $50 \%$ of cases) $)^{13,14,15,16}$.

Acute motor axonal neuropathy is observed in $10-20 \%$ of cases of GBS in the Western world, and in $60-70 \%$ of cases of GBS in northern China ${ }^{13,14,15,16}$.

There is a severe clinical form of GBS, as well as a mild form with distal involvement exclusively, and rapid recovery. Acute sensory-motor axonal neuropathy is the rarest, most severe subtype. Miller Fisher syndrome, another subtype of GBS, causes mild and transient weakness associated with external ophthalmoplegia, ataxia and areflexia.

Variants of GBS (including the paraparetic subtype and the saltatory subtype) can cause acute muscle weakness ${ }^{5,15}$. Diagnosis is based on clinical features meeting Asbury's diagnostic criteria for GBS, and it is confirmed by detecting the albumin-cytological dissociation in cerebrospinal fluid after the first week of illness. Neurophysiological studies show slow/blocked nerve conduction, or prolonged/absent $\mathrm{F}$ waves. Spinal cord MRI shows hyperintense nerve roots.

The treatment of choice is intravenous immunoglobulin (2 g/kg bodyweight, administered over 48 hours). Plasmapheresis may be considered (total exchange: 4 plasma volumes).

The prognosis of GBS in children is good, with a full recovery in $90 \%$ of cases. The remaining $5-10 \%$ of patients may develop minor motor or sensory sequelae..$^{15,16}$

\section{Porphyric Neuropathy}

Porphyria occurs as the consequence of an enzymatic defect (deficit of erythrocyte uroporphyrinogen-I-synthetase). The acute-intermittent clinical variant is expressed as peripheral neuropathy, starting with proximal weakness of lower limbs and areflexia. Further involvement of upper extremities, cranial nerve impairment, and respiratory failure 
may appear. Autonomic dysfunction (abdominal pain, diarrhea, bladder dysfunction) is an occasional feature ${ }^{1,4,5}$.

\section{Heavy-metal Poisoning}

Lead poisoning and arsenic poisoning can cause acute neuropathy with weakness and hyperreflexia. For this reason, toxicological work-up is essential in children with acute muscle weakness ${ }^{1,17}$.

\section{Critical Illness Polyneuropathy}

Critical illness polyneuropathy in pediatrics is expressed as a picture of acute weakness in patients with sepsis, infection or multisystemic failure under mechanical ventilation, who have been treated with neuromuscular blockers, corticosteroids and/or aminoglycoside antibiotics. It is the most common cause of neuromuscular disease in critically ill patients. It is suspected by the appearance of weakness and predominantly distal areflexia, and a delayed weaning from, or removal of, mechanical ventilation. The prognosis is favorable. It is associated with myopathy; therefore, it is now called critical illness polyneuropathy and myopathy ${ }^{18}$.

\section{DISORDERS OF THE NEUROMUSCULAR JUNCTION}

The neuromuscular junction is formed by the presynaptic nerve terminal, the synaptic cleft (site of action of acetylcholinesterase) and postsynaptic ionotropic muscle receptors. Disorders of the union or neuromuscular junction leading to acute muscle weakness may affect any of these three levels (presynaptic, synaptic and post-synaptic). Autoimmune myasthenia gravis is the paradigm of neuromuscular junction disorders, some of which are described below.

\section{Presynaptic disorders}

\section{Botulism}

Botulism is an acute form of poisoning. In adults and older children, it results from the ingestion of spoiled preserved (canned) foods; in pediatric clinical practice, it may manifest as infant botulism, described by Pickett, et al. in $1976^{19}$. This is a toxin-related intestinal infection caused by Clostridium botulinum, which multiplies in the intestines and releases botulinum toxin. The toxin is absorbed in the intestine and passes into the bloodstream, reaching the neuromuscular junction, where it irreversibly blocks the release of acetylcholine at the nerve terminal. It is most common in the USA, Australia and Argentina, but botulism cases have been described worldwide. In Chile, we have diagnosed 11 cases in a 30-year period, and the first confirmed case occurred in $1984^{20}$. Clinical onset includes constipation, hypotonia and cephaloparesis. Afterwards, generalized hypotonia, ptosis, ophthalmoparesis, and facial diparesis can be observed; generalized weakness with hyperreflexia and respiratory failure may appear in severe cases. Hyporeactive mydriasis is highly suggestive of the diagnosis, but it is not always present. In our series, only four of the eight infants had this sign. The diagnosis is confirmed by isolating Clostridium botulinum in cell cultures, and/or detection of the botulinum toxin in stool by toxin-neutralization tests in mice. The incremental pattern response to repetitive nerve stimulation at high frequencies is also helpful. There is no specific treatment other than supportive care. The use of aminoglycosides or antibiotics that destroy Clostridium membranes may lead to an increased release of the toxin and should be avoided. Specific immunoglobulin therapy may be useful if given promptly. Prognosis is very good and clinical improvement can be noticed after a 15-90-day period.

\section{Spider Venom}

The black widow spider (latrodectus mactans or "wheat spider" in South America) bite produces a massive release of acetylcholine at the nerve terminals of the neuromuscular junction. Hypertonia can be observed initially, which then evolves to hypotonia, muscle weakness and muscarinic changes (flushing, increased sweating). The bite of the latrodectus mactans leaves no mark on the $\operatorname{skin}^{2,21,22}$.

\section{Paralytic shellfish poisoning}

Ingestion of bivalve shellfish containing saxitoxin can cause acute muscle weakness with oral and facial paresthesias at onset, due to blockage of distal axonal nerve conduction. Its occurrence is rare in children. It is treated with early, appropriate supportive care ${ }^{1.3}$.

\section{Tick paralysis}

This entity can be found in the USA and Australia, where some species of ticks produce a powerful neurotoxin. Five or six days after the toxin penetrates the skin, generalized weakness, dysphagia, and dysarthria may develop. These symptoms decline rapidly after the tick is removed from the site of the bite, which is generally located in the posterior cervical area. ${ }^{2,3,23}$

\section{Synaptic disorders}

\section{Organophosphate poisoning}

Organophosphate poisoning causes increased cholinergic activity, destroying central and peripheral acetylcholinesterase. The associated effect is the appearance of muscarinic, nicotinic and central signs: dyspnea, increased respiratory secretions, sweating, salivation, lacrimation, myosis, muscle twitching and cramps, muscle weakness, convulsions and coma. Measurement of serum 
acetylcholinesterase is a quick method of diagnosing insecticide poisoning. The main treatment for this condition is atropine $(0.05 \mathrm{mg} / \mathrm{kg}$ every $15-20$ minutes until a favorable ventilatory response is achieved) and IV pralidoxime $(25-50 \mathrm{mg} / \mathrm{kg})^{2}$.

\section{Postsynaptic disorders}

\section{Autoimmune myasthenia gravis}

Autoimmune myasthenia gravis, a neuromuscular disorder caused by the blockade of acetylcholine receptors by specific antibodies that prevent muscle contraction ${ }^{24}$, may express as acute muscular weakness during a myasthenic crisis, which is caused by massive acetylcholine receptor blockade. Quadriplegia with normal reflexes is a remarkable finding, and it is associated with ptosis, ophthalmoparesis, swallowing disorder and respiratory failure. The administration of anticholinergic drugs is not effective, since there are not enough receptors susceptible to be activated by acetylcholine. Treatment is based on ventilatory support, plus IV immunoglobulin ( $1 \mathrm{~g} / \mathrm{kg}$ in 24 hours) or plasmapheresis (4-5 plasma volumes). After clinical recovery starts, corticosteroids are needed for a long period ${ }^{25,26}$.

\section{MUSCULAR DISEASES}

\section{Acute infectious myositis}

Benign acute infectious myositis of childhood is a condition that affects children exclusively, and it is caused by influenza virus (A, B) or enterovirus. It is characterized by myalgias predominantly affecting the gastrocnemius muscles, with a secondary difficulty or inability to walk, which is initially interpreted as acute paresis or paralysis. Elevated creatine kinase confirms the diagnosis. Symptoms persist for two to seven days. Exceptionally, there may be rhabdomyolysis and renal failure (creatine kinase values over 10,000-90,000 ${ }^{27}$.

In these cases, it is important to rule out the diagnosis of a metabolic myopathy.

\section{Polymyositis/dermatomyositis}

Polymyositis/dermatomyositis, well defined as subacute muscle autoimmune microangiopathy, may be a rare cause of acute muscle weakness. The clinical picture of generalized weakness with palpebral edema and palpebral/facial heliotrope erythema, associated with hyperCKemia, guides the diagnosis. This is confirmed by muscle biopsy showing perifascicular inflammation and atrophy. The EMG and muscle resonance may aid in diagnosis. The treatment of choice includes corticosteroids and immunosuppressants for six to 12 months or longer ${ }^{3-5}$.

\section{Familial periodic paralysis}

Familial periodic paralysis is a genetic, autosomal dominant disease that affects the sodium/potassium pump of the muscle cells. The most frequent periodic paralysis type 1 (CACNA1S mutation) and also the rarest periodic paralysis type 2 (SCN4A mutation) ${ }^{28}$ produce acute muscle weakness associated with hypokalemia, which appears hours after the initial triad: history of exercise, high intake of carbohydrates and subsequent sleep. Unsurprisingly, most episodes occur upon awakening in early morning. Another form of dyskalemic paralysis, hyperkalemic paralysis (SCN4A mutation), associated with myotonia, produces short-term weakness only, with a duration of minutes in some cases. The history of previous episodes and/or more affected relatives, as well as the detection of severe hypokalemia (less than $2 \mathrm{mEq} / \mathrm{l}$ ) can confirm diagnosis. Treatment of choice is acetazolamide. Secondary hypokalemias can produce potential paralysis s $^{3,4,5}$.

\section{Critical illness myopathy}

Pediatric critical illness myopathy was first described in children with asthma attacks, receiving mechanical ventilation, and undergoing treatment with corticosteroids and neuromuscular blockers. Subsequently, a necrotizing myopathy affecting type II fibers rich in myosin, associated with high creatine phosphokinase levels, was described ${ }^{29}$.

Weakness is predominantly proximal, and myotatic reflexes are present. The diagnosis can be confirmed by muscle biopsy, but the transient nature of this condition does not justify this procedure, except when a congenital myopathy is suspected. Exceptionally, congenital myopathy can be expressed as acute muscle weakness with areflexia due to an intercurrent infectious process, as we observed in a preschooler with mild myotubular myopathy and a concurrent influenza B infection.

\section{Psychogenic cause - Psychogenic paralysis}

Psychogenic paralysis is often difficult to diagnose, and it can be suspected only if all the possible organic causes have been discarded. The most severe cases can last months or more than a year ${ }^{30}$.

\section{CONCLUSIONS}

Acute muscle weakness in children is an emergency that must be addressed in an effective and timely manner, in order to achieve an accurate diagnosis and to start early, appropriate treatments. A practical approach to the etiologic diagnosis of acute muscle weakness in children is shown in the flowchart of the Figure. 


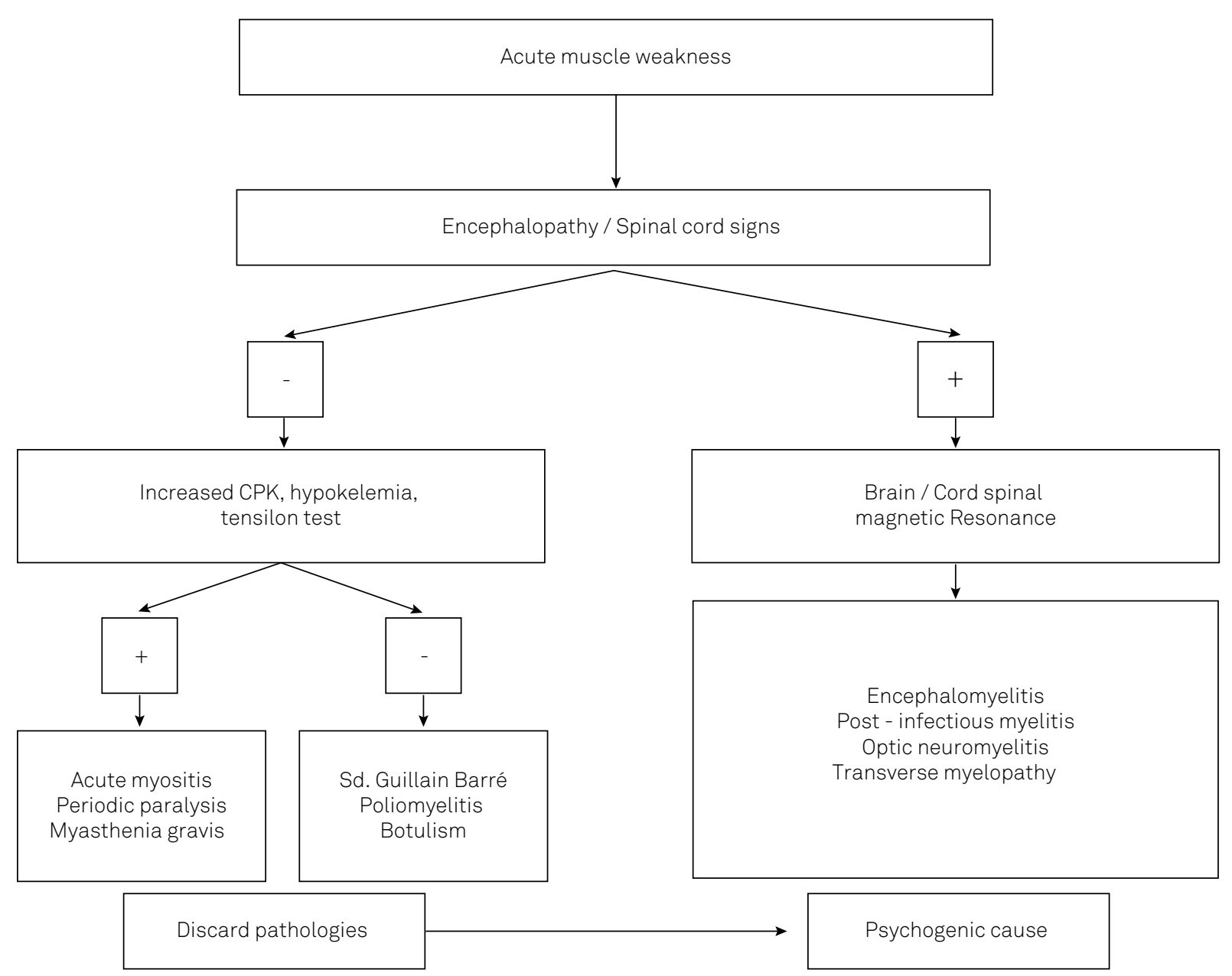

Figure. General approach to acute muscle weakness.

\section{References}

1. Oostvogel PM, Spaendonck MA, Hirasing RA, Loon AM. Surveillance of acute flaccid paralysis in the Netherlands. Bull World Health Org. 1998;76(1):55-62.

2. Leshner RT, Campbell WW. Pediatric neuromuscular emergencies. In: Pellock JM, Myer EC, editors. Neurologic emergencies. Philadelphia: Harper and Row; 1984.

3. Erazo R. Parálisis flácida aguda. Rev Chil Pediatr. 1995;66(Suppl 1):9-13.

4. Campos-Olazábal P. Parálisis flácida aguda. Rev Neurol. 2002;34(2):131-3.

5. Antoniuk SA. Debilidad muscular aguda: diagnósticos diferenciales. Rev Neurol 2013;57(Suppl 1):S149-54.

6. Medical Research Council. Aids to the examination of the peripheral nervous system. London: Her Majesty's Stationery Office; 1981. (Memorandum, No 45).

7. Acute flaccid paralysis surveillance: a global platform for detecting and responding to priority infectious diseases. Wkly Epidemiol Rec. 2004;79(48):425-32.

8. Tenembaum S. Acute disseminated encephalomyelitis. In: Dulac O, Lassonde M, Sarnat HB, editors. Pediatric neurology Part II. Amsterdam: Elsevier; 2013. p. 1255-62. (Handbook of clinical neurology, Vol 112).

9. Reynolds T. Polio: an end in sight? BMJ. 2007;335(7625):852-4. https://doi.org/10.1136/bmj.39367.426655.AD

10. Jasem JA, Marof K, Nawar A, Khalaf I, Al-Hamdani S, Ali A et al. Surveillance of acute flaccid paralysis in Iraq: 1998 to 2011. BMC Infect Dis. 2014;11(3):164-73. https://doi.org/10.1186/1471-2334-14-448
11. Huang CC, Liu CC, Chang YC, Chen CY, Wang ST, Yeh TF. Neurologic complications in children with enterovirus 71 infection. N Engl J Med. 1999;341(13):936-42. https://doi.org/10.1056/NEJM199909233411302

12. Leis AA, Stokic DS, Polk JL, Dostrow V, Winkelmann M. A poliomyelitislike syndrome from West Nile virus infection. N Engl J Med. 2002;347(16):1279-80. https://doi.org/10.1056/NEJM2002c021587

13. Asbury AK. New concepts of Guillain-Barré syndrome.J Child Neurol. 2000;15(3):183-91. https://doi.org/10.1177/088307380001500308

14. Sladky JT. Guillain-Barré syndrome. In: Jones HR Jr, De Vivo DH, Darras BT, editors. Neuromuscular disorders of infancy, childhood and adolescente: a clinical approach. Oxford: Butterworth Heinemann; 2003. p. 407-44.

15. Erazo Torricelli R. Síndrome de Guillain Barré en pediatría. Medicina (B. Aires). 2009;69(1 supp 1):84-91.

16. Korinthenberg R. Acute polyradiculoneuritis: Guillain-Barré syndrome. Handb Clin Neurol. 2013;112:1157-62. https://doi.org/10.1016/B978-0-444-52910-7.00036-2

17. Keka A, Ramosaj A, Toro H, Azemi M, Baloku A, Sylaj B et al. Acute poisoning in children: changes over the years, data of pediatric clinic department of toxicology. J Acute Dis. 2014;3(1):56-8. https://doi.org/10.1016/S2221-6189(14)60012-3

18. Kukreti V, Shamim M, Khilnani P. Intensive care unit acquired weakness in children: critical illness polyneuropathy and myopathy. Indian J Crit Care Med. 2014;18(2): 95-101. https://doi.org/10.4103/0972-5229.126079 
19. Pickett J, Berg B, Chaplin E, Brunstetter-Shafer MA. Syndrome of botulism in infancy: clinical and electrophysiologic study. N Engl J Med. 1976;295(14):770-2. https://doi.org/10.1056/NEJM197609302951407

20. Erazo R, Marambio E, Cordero J, Fielbaum O, Triviño X. Botulismo infantil: comunicación de un caso. Rev Med Chil. 1987;115(4):344-8.

21. Erazo R. Miastenia gravis y síndromes miasténicos en el niño. Rev Chil Pediatr. 1990;61(5):287-90.

22. Schenone H. Cuadros tóxicos producidos por mordeduras de araña en Chile: latrodectismo y loxoscelismo. Rev Med Chil. 2003;131(4):437- 44. https://doi.org/10.4067/S0034-98872003000400013

23. Gothe R, Kunze K, Hoogstraal H. The mechanisms of pathogenicity in the tick paralyses. J Med Entomol. 1979;16(5):357-69. https://doi.org/10.1093/jmedent/16.5.357

24. Papazian O, Alfonso I, Araguez N. Miastenia gravis juvenil. Medicina (B. Aires). 2009;69(1 suppl 1):71-83.

25. Wendell LC, Levine JM. Myasthenic crisis. Neurohospitalist .2011;1(1):16-22. doi:10.1177/1941875210382918
26. Bird SJ, Levine JM. Myasthenic crisis. UpToDate. 2014 [cited 2016 Jan 27]. Available from: http://www.uptodate.com/ contents/myasthenic-crisis

27. Mackay MT, Kornberg AJ, Shield LK, Dennett X. Benign acute childhood myositis. laboratory and clinical features. Neurology. 1999;53(9):2127-31. https://doi.org/10.1212/WNL.53.9.2127

28. Miller TM, Silva MRD, Miller HA, Kwiecinski H, Mendell JR, Tawil R et al. Correlating phenotype and genotype in the periodic paralyses. Neurology. 2004;63(9):1647-55. https://doi.org/10.1212/01.WNL.0000143383.91137.00

29. Williams S, Horrocks IA, Ouvrier RA, Gillis J, Ryan MM. Critical illness polyneuropathy and myopathy in pediatric intensive care: a review. Pediatr Crit Care Med. 2007;8(1):18-22. https://doi.org/10.1097/01.pcc.0000256623.01254.40

30. Maida AM, Molina ME, Erazo R. [Münchausen-by-proxy syndrome: report of one case]. Rev Med Chil. 2001;129(8):917-20. Spanish. https://doi.org/10.4067/S0034-98872001000800011 